\title{
Impact of Climate Change on Cotton Production: Case of Savannah Region, Northern Togo
}

\section{Mawussi Kossivi Soviadan ${ }^{1 *}$, Egnonto Mitowanou Koffi-Tessio ${ }^{2}$, Anselm Anibueze Enete ${ }^{1}$, Noble Jackson Nweze ${ }^{1}$}

\author{
${ }^{1}$ Department of Agricultural Economics, University of Nigeria, Nsukka (UNN), Nsukka, Nigeria \\ ${ }^{2}$ Department of Agricultural Economics, Université de Lomé, Lomé, Togo \\ Email: *mawussikossivisoviadan@gmail.com
}

How to cite this paper: Soviadan, M.K., Koffi-Tessio, E.M., Enete, A.A. and Nweze, N.J. (2019) Impact of Climate Change on Cotton Production: Case of Savannah Region, Northern Togo. Agricultural Sciences, 10, 927-947.

https://doi.org/10.4236/as.2019.107071

Received: June 4, 2019

Accepted: July 16, 2019

Published: July 19, 2019

Copyright $\odot 2019$ by author(s) and Scientific Research Publishing Inc. This work is licensed under the Creative Commons Attribution International License (CC BY 4.0).

http://creativecommons.org/licenses/by/4.0/

\begin{abstract}
Among the numerous problems that are facing cotton farmers, climate change is one of the most important still out of their control. Adaptation appears to be one of the best alternatives. The objective of this research is to assess the impact of climate change on cotton production in the Savannah region of Togo. The study was conducted with 172 cotton farmers sampled randomly in many stages in order to determine the impact of climate change on cotton production. The impact assessment of climate change on cotton production was carried out using ATE (Average Treatment Effect) and ATET (Average Treatment Effect on the Treated) models introduced by Rubin in 1974. The results show that climate change has a significant negative impact at $1 \%$ level on cotton production observed with an average decrease per farmer of 2330 $\mathrm{kg}$, on the yield efficiency with an average decrease of $515 \mathrm{~kg} / \mathrm{ha}$ and on the income level with an average decrease of US $\$ 745$ per farmer. Climate change reduces the level of soil fertility, favours pest resistance and leads to an increase in consumption of cotton production inputs per unit of area. The study also reveals a low level of adaptation of cotton farmers to climate change. The expansion of cultivated areas remains the main reaction of cotton farmers to climate's negative effects. Raising producers' awareness on the reality of climate change and adopting adaptation techniques and strategies would greatly improve cotton farmers' adaptive capacity and positively affect cotton production in Savannah region, and Togo in general.
\end{abstract}

\section{Keywords}

Climate Change, Cotton Production, Impact, ATE-ATET, Savannah Region, Togo 


\section{Introduction}

In Togo, like in many West African countries, agriculture remains the main driving force for economic and social development. Togolese agriculture is a major issue in terms of economic weight, employment, source of income and food security [1]. While food crops are contributing $68.5 \%$ to the formation of the Gross Domestic Agricultural Product (GDAP), annuity products (cotton, coffee and cocoa) contribute $9 \%$ to the GDAP [2].

The cotton sector most remains an engine of growth as well as in rural areas and in the national economy. It is the most structured agricultural sub-sector which guarantees producers an annual income. However, its performance has not always succeeded in eradicating the poverty of farmers who are involved in the sector. The optimization of agricultural production in general and cotton production in particular necessarily requires good productivity and therefore good level of land yield.

Cotton fiber is the fourth export product after clinker, cement and phosphates in Togo. Cotton is thus the first cash crop and represents one of the country's main sources of agricultural income. It contributes $20 \%$ to $40 \%$ of export revenues depending on the level of production and between $1 \%$ and $4.3 \%$ of GDP depending on the year. Today, the yield for cotton production at the national level in general and in the Savannah region in particular has not exceeded 900 $\mathrm{kg} / \mathrm{ha}$ since more than 10 years [3]. Thus the low level of field yields becomes a structural problem that does not allow producers to optimize their production. This situation is detrimental to the sustainability of the cotton sector as it does not allow producers to take maximum advantage of their crop production [3]. Over the past ten years, there has been a permanent disruption of the rainfall regime. Rainfall is irregular and unevenly distributed over time and space. Technical recommendations for sowing dates have become very difficult to observe under these conditions. The dates of crop maintenance, manure, phytosanitary treatments and harvests are disrupted and compromised by rainfall troughs, pockets of drought and/or floods. It is becoming important to analyze the impact of rainfall on cotton production in recent years and make technical suggestions that would allow producers to reduce as much as possible the impact of rainfall on their cotton trees and thus reduce poverty [3]. Several factors influence agricultural performance, but climate change is increasingly recognized as the key factor determining the form, importance and time structure of agricultural productivity [4]. Climatic conditions exacerbated by frequent disruptions such as droughts, floods and storms that have been growing steadily in recent years are signs of the reality of climate change. According to [5], climate change is one of the most complexes, multifaceted and serious threats facing the world. Many studies on the relationship between agricultural performance and climate effects in recent years at the global, regional and national levels agree that climate change can significantly reduce agricultural productivity worldwide and severely affect rural communities due to their limited adaptive capacities and 
high dependence on climate-sensitive resources such as water resources and agricultural production systems [4] [6]-[12]. [13] points out that forecasts of higher average temperatures and changes in rainfall patterns will have a negative impact on agricultural production. The effects of climate change on cotton production are manifested in increased temperature, irregular rainfall, soil degradation and, in turn, lower production, productivity and quality degradation of cotton [14]. Cotton requires at least 600 to $800 \mathrm{~mm}$ of water for the duration of its growing cycle, and its needs are higher between the beginning of flowering and the opening of the capsules. As soon as the capsules mature, the dry period should be as perfect as possible to preserve quality. A situation that is not obvious with the phenomenon of climate change. And this has an impact on cotton production [14]. Togo, like the rest of the world, is experiencing changes in its rainfall and temperature patterns due to global climate change [8]. Climate change then appears as one of the challenges to cotton production in Togo since cotton production is climate-dependent. Therefore, the development of appropriate strategies that can mitigate the effects of the interaction between cotton production and climate change for a long-term cotton policy should include a study of the impact of climate change on cotton production and the vulnerability of cotton farmers. It is in this perspective that the present research aims to assess the impact of climate change on cotton production and productivity in the Savannah region in order to suggest adaptive solutions to improve the performance of the cotton sector in Togo. The choice to carry out this research in the Savannah region is explained by the low levels of agricultural production and productivity in general and cotton production in particular observed in recent years in this area and its vulnerability to the adverse effects of climate change. The objective of this investigation is to assess the impact of climate change on cotton production in the Savannah region. Specifically, this study aims to evaluate the impact of climate disruptions such as irregularity and the variability in the rainfall distribution on cotton production in the Savannah region, assess the adaptation measures used by vulnerable cotton farmers to cope with the adverse effects of climate change on their crops and finally contribute to knowledge in the field of agricultural economics.

\section{Materials and Methods}

\subsection{Study Area}

The study was carried out among cotton producers of the Savannah region in 2011/2012 and 2015/2016 cotton production seasons. Located in the far north of Togo, the Savannah region lies within latitudes $10^{\circ} 30^{\prime}$ North and longitudes $0^{\circ} 30^{\prime}$ East covering an approximate area of 8602 square kilometres, or $15 \%$ of the national territory. It is bordered to the South by the Kara region, to the North by Burkina-Faso, to the East by the Republic of Benin and to the West by Ghana. It is divided administratively into seven prefectures: Oti, South Oti, Tandjoare, Tone, Cinkasse, Kpendjal and Western Kpendjal. The average population densi- 
ty in the Savannah region is estimated at 90 inhabitants per square kilometres, the national average being estimated at 101 inhabitants per square kilometres. The population of the Savannah region is mainly rural. The dominant activity of the region is agriculture which employs nearly $90 \%$ of the population.

\subsection{Data Sources}

\subsubsection{Meteorological Data}

Monthly temperature and rainfall data from 1980 to 2015, collected from the Meteorological Station of the Savannah region were used to run analyses.

\subsubsection{Primary Data Collection}

The primary data were collected by using a survey sheet consisting of a questionnaire administered to the sampled cotton producers.

\subsubsection{Stratified Sampling}

The study focused exclusively on cotton producers in the region. The sample size selected for this research is based on the following sample calculation formula, with $95 \%$ confidence and a maximum variability of $50 \%$ :

$$
n=\frac{N}{1+N \times e^{2}}
$$

Source: [15]

where:

$N$ is the size of the target population (all cotton farmers in the Savannah region),

$n$ is the sample size,

$e$ is the precision level.

Given the similarity or high degree of homogeneity of the cotton farmers in the region according to their common characteristics, the precision level used to calculate the sample is $\pm 8 \%$.

\subsubsection{Calculation of the Sample Size}

The level of precision used is $\pm 8 \%$, and the size of the total population is equal to 52,239 cotton farmers. The calculation formula gives the following sample size $(n): n=52,239 /(1+52,239 \times(0.08 \times 0.08))=52,239 / 335=156$ cotton farmers. Adding $10 \%$ absorbing losses from field surveys, the sample size (n) is equal to 172 cotton farmers.

\subsubsection{Sample Size per Stratum}

The Savannah region is constituted by 35 cotton production zones located in seven prefectures. Knowing the total number of cotton farmers in the region and by cotton production zone, we assigned a weight to each stratum (production zone). Thus the sample size of each stratum, i.e. cotton production zone, is obtained by multiplying the size of the general sample by the weight of each stratum. Table 1 illustrates the complete sampling plan of the study. 
Table 1. Full study sampling design.

\begin{tabular}{|c|c|c|c|c|c|}
\hline Prefecture & No. & $\begin{array}{l}\text { Label of the } \\
\text { production zone }\end{array}$ & $\begin{array}{l}\text { Number of cotton } \\
\text { producers in the zone }\end{array}$ & $\begin{array}{l}\text { Weight of the } \\
\text { zone (\%) }\end{array}$ & $\begin{array}{l}\text { Number of cotton producers from } \\
\text { each zone and included in the sample }\end{array}$ \\
\hline \multirow{8}{*}{ TONE } & 1 & Dapaong & 1244 & 2.38 & 4 \\
\hline & 2 & Djangou & 1689 & 3.23 & 6 \\
\hline & 3 & Korbongou & 2160 & 4.13 & 7 \\
\hline & 4 & Lotogou & 1614 & 3.10 & 5 \\
\hline & 5 & Nadoundi Total & 2492 & 4.80 & 8 \\
\hline & 6 & Naki-Ouest & 1940 & 3.70 & 6 \\
\hline & 7 & Pana & 1959 & 3.75 & 6 \\
\hline & 8 & Tidonte & 3003 & 5.75 & 10 \\
\hline \multirow{2}{*}{ CINKASSE } & 9 & Biankouri & 966 & 1.85 & 3 \\
\hline & 10 & Timbou & 1259 & 2.41 & 4 \\
\hline \multirow{6}{*}{ TANDJOARE } & 11 & Bogou & 831 & 1.60 & 3 \\
\hline & 12 & Bombouaka & 1015 & 1.94 & 3 \\
\hline & 13 & Loko & 823 & 1.58 & 3 \\
\hline & 14 & Nano & 985 & 1.88 & 3 \\
\hline & 15 & Nolbagou & 604 & 1.16 & 2 \\
\hline & 16 & Yembour & 597 & 1.14 & 2 \\
\hline \multirow{7}{*}{$\begin{array}{c}\text { KPENDJAL AND } \\
\text { WESTERN KPENDJAL }\end{array}$} & 17 & Bagré & 463 & 0.88 & 2 \\
\hline & 18 & Koundjoaré & 1492 & 2.86 & 5 \\
\hline & 19 & Kpendjaga & 2506 & 4.80 & 8 \\
\hline & 20 & Naki-Est & 1837 & 3.52 & 6 \\
\hline & 21 & Namoudjoga & 1320 & 2.53 & 4 \\
\hline & 22 & Ogaro & 2683 & 5.14 & 9 \\
\hline & 23 & Yiegou & 2127 & 4.07 & 7 \\
\hline \multirow{12}{*}{$\begin{array}{l}\text { OTI AND } \\
\text { SOUTH OTI }\end{array}$} & 24 & Barkoissi & 1798 & 3.44 & 6 \\
\hline & 25 & Gando & 2291 & 4.39 & 8 \\
\hline & 26 & Mango & 714 & 1.37 & 2 \\
\hline & 27 & Mogou & 1479 & 2.83 & 5 \\
\hline & 28 & Nagbeni & 1567 & 2.99 & 5 \\
\hline & 29 & Nali & 826 & 1.58 & 3 \\
\hline & 30 & Panga & 1182 & 2.26 & 4 \\
\hline & 31 & Sagbiebou & 1289 & 2.46 & 4 \\
\hline & 32 & Takpamba & 1323 & 2.53 & 4 \\
\hline & 33 & Tchamonga & 1699 & 3.25 & 6 \\
\hline & 34 & Tchanaga & 1094 & 2.09 & 4 \\
\hline & 35 & Tontondi & 1368 & 2.61 & 5 \\
\hline \multicolumn{3}{|c|}{ TOTAL SAVANNAH REGION } & 52239 & 100 & 172 \\
\hline
\end{tabular}

Source: Based on data from NSCT/Dapaong, 2015. 
A total of one hundred and seventy-two (172) cotton farmers spread over all cotton production zones in the region were interviewed. Following the results of the meteorological data analyses of the last 36 years and specifically those of 2011 and 2015, the primary data collection concerned two cotton production seasons (2011/2012 and 2015/2016). The 2011/2012 cotton production season was considered as the reference season, i.e. during this production season, the climatic conditions were favourable to cotton farms and the 2015/2016 cotton production season as the one during which cotton farms were strongly affected by climate change (target cotton season).

\subsection{Analysis Method}

\subsubsection{Theory of Change}

As agriculture in general and cotton production in particular is rainfed in Togo, climate change, an exogenous and random phenomenon resulting in poor rainfall distribution over time and space and over which cotton farmers have no control, will necessarily have a considerable impact on cotton production. It is on the basis of this theory of change that the hypotheses of this study are formulated and which, a priori, seem to answer the central research questions. However, they will be confirmed or denied based on the results of our empirical analyses.

\section{1) Analysis of Rainfall Trends in the Savannah Region}

The analysis of rainfall parameters has made it possible to examine possible changes over the past thirty-six (36) years. Figure 1 and Figure 2 give us an

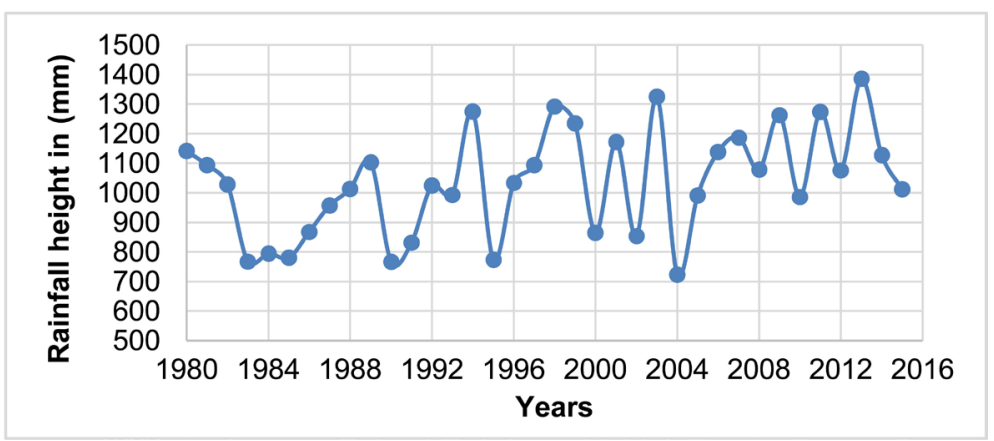

Source: Data from the Meteorological Station in the Savannah Region (1980-2015).

Figure 1. Interannual evolution of rainfall in the Savannah Region.

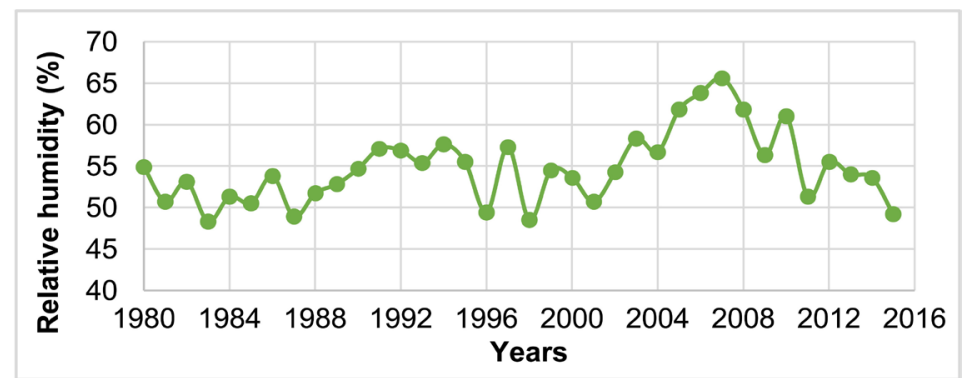

Source: Data from the Meteorological Station in the Savannah Region (1980-2015).

Figure 2. Evolution of the annual relative humidity. 
overview of the evolution of annual rainfall amounts from 1980 to 2015, and relative humidity.

\section{2) Analysis of Thermometric Trends}

Apart from rainfall, temperature is a climatic parameter that affects the living environment of both cotton producers and their farms. The evolution of temperature over the last thirty-six (36) years is presented in Figure 3. The analysis in Figure 1 shows an irregularity and poor distribution of annual rainfall heights with a downward trend. Figure 2 shows a variation in annual relative humidity with a downward trend.

The annual thermometric trend presented in Figure 3 shows that there has been an annual increase in temperatures since 1987. Since 2012, the region has been recording an increasing annual thermometric trend. The analysis of these three figures (Figure 1, Figure 2 and Figure 3) show that for the years 2011 and 2015 in the Savannah region, the rainfall is higher in 2011 than 2015, respectively $1273 \mathrm{~mm}$ against $1011 \mathrm{~mm}$.

Thus, 2011 was relatively wetter than 2015 . On the other hand, in terms of temperature, 2015 was relatively warmer than 2011 , with $34.55^{\circ} \mathrm{C}$ versus $33.6^{\circ} \mathrm{C}$ for the maximum temperature, $23.1^{\circ} \mathrm{C}$ versus $22.9^{\circ} \mathrm{C}$ for the minimum temperature and $28.8^{\circ} \mathrm{C}$ versus $28.2^{\circ} \mathrm{C}$ for the average annual temperature respectively. A brief analysis of the monthly rainfall data for 2011 and 2015 over a period of five consecutive years revealed in particular whether or not the climatic conditions were favourable to cotton production during the 2011/2012 and 2015/2016 agricultural production seasons.

3) Comparative Analysis of Monthly Meteorological Data for 2011 and 2015

The analysis of Figure 4 shows that in 2011, rains were abundant, regular and well distributed, especially over the cotton growing periods (April, May, June, July), while in 2015, they were rare, irregular and unevenly distributed. All other things being equal, it can be deduced from this analysis that climatic conditions such as rainfall were favorable to cotton production during the 2011/2012 cotton production season and unfavorable during the 2015/2016 cotton production season. Thus, in the rest of this study, it is necessary to consider the 2011/2012

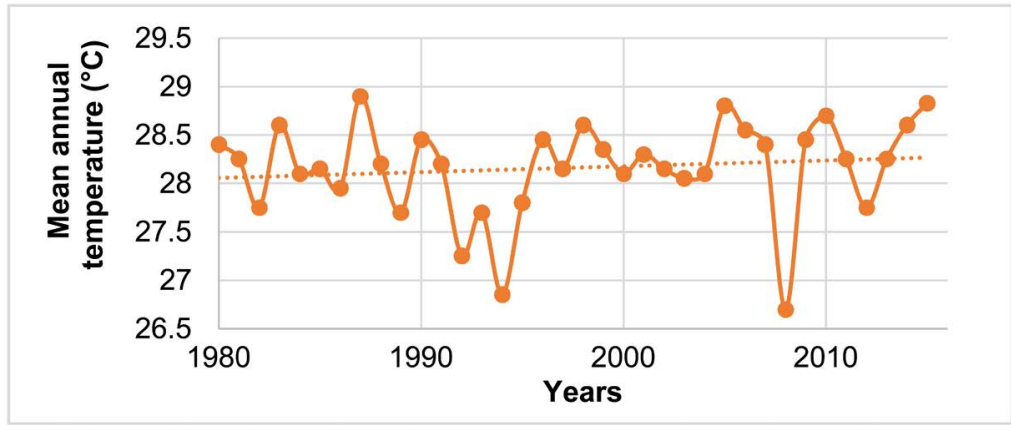

Source: Data from the Meteorological Station in the Savannah Region (1980-2015).

Figure 3. Mean annual temperature $\left({ }^{\circ} \mathrm{C}\right)$. 


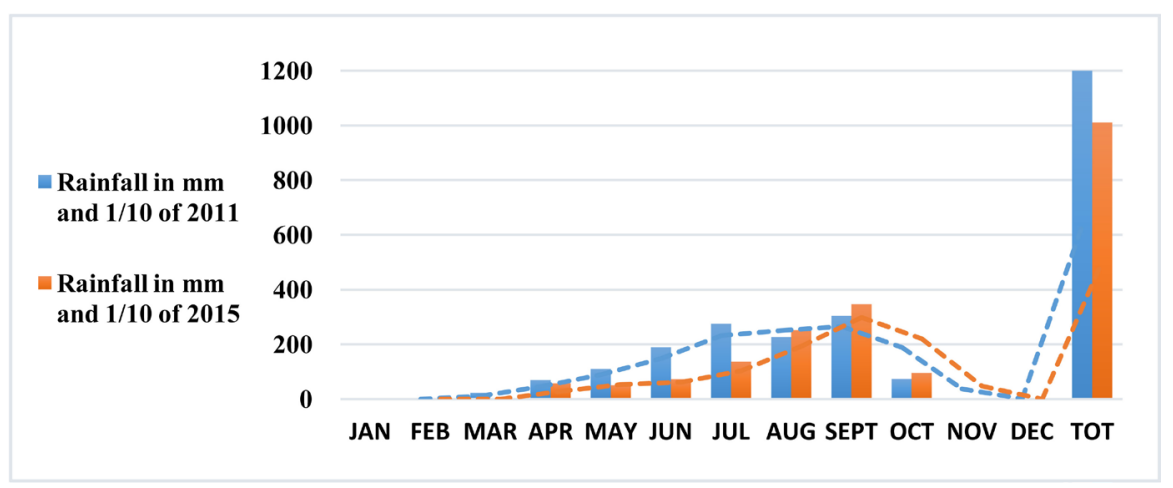

Source: Data from the Meteorological Station in the Savannah Region.

Figure 4. Monthly average rainfall in 2011 and 2015.

cotton production season as a reference season where cotton production has not been significantly impacted by "climate change" and the 2015/2016 cotton production season, the inverse and then conduct an impact analysis based on econometric tools. It is also essential to clarify that according to [16], the term "climate change" refers to changes in the climate status in terms of changes in the mean and/or variability of its parameters (temperature, precipitation, etc.) over a relatively long period, generally over several decades or more, due to natural causes and/or human activity. But in the rest of this research, more attention has been devoted to the precipitation factor (irregularity and poor rainfall distribution) since, among all climate parameters, rainfall is the most important factor that allows farmers to set up their crops given Togo's high dependence on rainfed agriculture [17].

\subsubsection{Theoretical Framework Formulation}

The rather general canonical model of evaluation, introduced by [18], is adapted to the situation in which treatment may or may not be given to an individual. The term treatment refers to the initial work that made it possible to develop this conceptual framework, work that concerned the evaluation of the effectiveness of treatments in the medical field. Although it is not the most appropriate, it is used in econometrics qualifying a public intervention, tax reform, subsidy poli$c y$, training program, agro climatic events or social assistance program that is being evaluated. Formally, for each individual in a sample size $N$, the following set of random variables will be observed. The fact that a farmer's agricultural exploitation is impacted (by climate change) is represented by a random variable $T$, which takes the value 1 if the cotton farm is impacted, 0 if otherwise.

The impact of climate change is measured through an outcome variable, noted $Y_{i}$. In fact, Rubin's model is based on the existence of two latent outcome variables, noted $Y_{1}$ and $Y_{0}$, depending on whether the production is impacted $(T=1)$ or not $(T=0)$. These variables correspond to the potential results of the impact of climate change on the outcome variables $\left(Y_{i}\right)$. They are never simultaneously observed on the same date for the same cotton producer. Thus, when a 
producer's cotton farm is impacted, $Y_{1}$ is observed while $Y_{0}$ is unknown. In this case, variable $Y_{0}$ corresponds to the result that would have been achieved if the cotton farm had not been affected. It is also said that the variable $Y_{0}$ represents the counterfactual result. For non-impacted production, on the other hand, $Y_{0}$ is observed, while $Y_{1}$ is unknown.

The observed outcome variable can therefore be deduced from the potential variables and the treatment variable by the relationship:

$$
Y=T Y_{1}+(1-T) Y_{0}
$$

Only the torque $(Y, T)$ is observed for each cotton farmer.

\subsubsection{Parameters of Interest}

The treatment effect is defined for each cotton farm by the difference:

$$
\Delta=Y_{1}-Y_{0}
$$

which represents the difference between what the situation of the cotton farmer would be if his farm was impacted and what it would be otherwise. The causal effect thus has two important characteristics: it is unobservable, since only one of the two potential variables is observed for each cotton farmer; it is individual, and therefore there is a distribution of the causal effect in the population. However, the distribution of the causal effect is not identifiable, simply because the causal effect is unobservable. Nevertheless, thanks to hypotheses on the attached law of the triplet $\left(Y_{1}, Y_{0}, T\right)$, it is possible to identify some parameters of the distribution of the causal effect from the density of the observable variables $(Y, T)$. Two parameters are generally the subject of a specific examination.

It is about:

The average treatment effect in the population (cotton farms in 2011 and 2015):

$$
A T E=E\left(Y_{1}-Y_{0}\right)
$$

And the average treatment effect in the population of farms impacted in 2015:

$$
A T E T=E\left(Y_{1}-Y_{0} \mid T=1\right)
$$

The difference between these two parameters constitute the selection bias noted $\beta$. If $\beta$ equal to zero, that means there is no selection bias, thus:

$$
A T E=E\left(Y_{1}-Y_{0}\right)=A T E T=E\left(Y_{1}-Y_{0} \mid T=1\right)
$$

The necessary and sufficient condition for having this equilibrium between $A T E$ and $A T E T$ is defined as follow:

$$
\operatorname{ATE}(x)=E\left(Y_{1} \mid X=x, T=1\right)-E\left(Y_{0} \mid X=x, T=0\right)
$$

and

$$
\operatorname{ATET}(x)=E\left(Y_{1} \mid X=x, T=1\right)-E\left(Y_{0} \mid X=x, T=1\right)
$$

The Equation (6) can be rewritten as follow: 


$$
\begin{aligned}
\operatorname{ATE}(x)= & E\left(Y_{1} \mid X=x, T=1\right)-E\left(Y_{0} \mid X=x, T=0\right) \\
= & {\left[E\left(Y_{1} \mid X=x, T=1\right)-E\left(Y_{0} \mid X=x, T=1\right)\right] } \\
& +\left[E\left(Y_{0} \mid X=x, T=1\right)-E\left(Y_{0} \mid X=x, T=0\right)\right]
\end{aligned}
$$

Then $\operatorname{ATE}(x)=\operatorname{ATET}(x)+\left[E\left(Y_{0} \mid X=x, T=1\right)-E\left(Y_{0} \mid X=x, T=0\right)\right]$

For $\beta=\left[E\left(Y_{0} \mid X=x, T=1\right)-E\left(Y_{0} \mid X=x, T=0\right)\right]$

where $\beta$ is the selection bias

The Equation (6) finally becomes:

$$
\operatorname{ATE}(x)=\operatorname{ATET}(x)+\beta
$$

$\operatorname{ATE}(x)=\operatorname{ATET}(x)$ if and only if $\beta=0 \quad$ [18] [19].

\subsubsection{Conceptual Framework}

The formulation of this conceptual framework leads to the following three questions: impact of what (climate change), on what (production) and for whom (cotton farmers in the Savannah region). The answer to this triptych makes it possible to determine the impact factors and results impacted on the target populations. With this "treatment effect" method, the key concepts of the estimation of the analysis model will be defined. The Average Treatment Effect (ATE) used will allow us to assess the impact of climate change on cotton production. The approach used in this study is the so-called counterfactual and non-experimental approach. It is based here on the impact factors and determinants induced by climate change, exogenous factors on which cotton producers do not have control over changes in their values such as poor rainfall distribution over cotton growing periods. The impact results sought relate to the level of production, productivity, income, etc. The challenge of impact assessment is that for each outcome there are several exogenous and endogenous impact factors that contribute to changes observed in that outcome. The fundamental question for this research is the following: What is the impact of climate change on cotton production if all factors, other than climate change, are controlled. To answer this fundamental question precisely, three associated fundamental sub-questions must be conceptually asked and answered:

1) The impact of what? 2) On what? And 3) For whom?

This research aims to study an answer to the first sub-question (of what?): climate change. In other words, it is proposed to assess the impact of rainfall distribution during the growing season. For the second sub-question (on what?), several answers will be studied: production, productivity, production area, pest resistance, input consumption, soil fertility and income. In other words, the impact of poor rainfall distribution on these different performance indicators. As for the third sub-question (for whom?), its answer is unique and invariable in this study: cotton producers in the Savannah region. The challenge of the "counterfactual" approach, on the other hand, is that it is based on the comparison of each result with its counterfactual; a comparison that is impossible to make in reality at the individual level, because by definition, one cannot observe 
a fact and its counterfactual. In other words, when there is an agro-climatic change, one cannot observe what the different outcomes would be without the change. Similarly, if the change does not occur, it is also impossible to observe what would happen if the change did occur. For example, in the case of impact assessment of climate change on cotton production, if $Y_{1}$ represents the potential production level of a given cotton farmer if his farm is affected by poor rainfall distribution and $Y_{0}$ otherwise, the treatment effect of climate change on production is defined as $Y_{1}-Y_{0}$. The problem is the identification. One cannot observe both the potential results $Y_{1}$ and $Y_{0}$ on the same individual at the same time because the individual is either impacted by climate change and his production level is $Y_{1}$ or he is not impacted and his production level is $Y_{0}$, but not both at the same time. Therefore, if $D$ is the binary variable indicating the status of climate change impact (with $D=1$ indicating impact and $D=0$ otherwise), it is only possible to observe:

$$
Y=D Y_{1}+(1-D) Y_{0}
$$

Since one of the potential output level results (with or without treatment) is still missing for the same individual (non-factual elements), it is not possible to calculate the treatment effect (climate change impact) $Y_{1}-Y_{0}$ for that individual.

\subsubsection{Model Specification}

The treatment effect $Y_{1}-Y_{0}$ is unobservable for each cotton producer. Thus, with reference to the model introduced by Rubin in 1974 developed above, the following average treatment $\operatorname{effect}(A T E)$ and average treatment effect on the treated $(A T E T)$ will be estimated:

$$
\begin{gathered}
A T E=E\left(Y_{1}-Y_{0}\right) \\
A T E T=E\left(Y_{1}-Y_{0} \mid D=1\right)
\end{gathered}
$$

\subsubsection{Choice of Control Variables}

The choice of control variables for estimation requires careful analysis because some variables impacted by climate change may violate the assumption of conditional independence. In summary, for each targeted result, the control variables must eliminate or minimize selection bias. However, to ensure that the conditional independence assumption that these variables must satisfy is not violated, the values of these control variables must be chosen from values prior to climate change and attribute variables whose values never change or change solely because of the passage of time. Once this choice has been made for each target result, a variable independence test should be performed to select variables that are not correlated to climate change or the target result (a necessary condition for a variable to have a causal influence). Following this remark, it is necessary to carry out a correlation test of the variables using the Pearson correlation test.

\subsubsection{Pearson Correlation Test}

The Pearson correlation test verifies the relationship between control variables 
and treatment variable in order to determine the appropriate control variables for estimating the ATE model.

\subsubsection{Significance Test between the Treatment Variable and the Outcome Variables \\ 1) Pearson Chi-Square Significance Test $\left(\chi^{2}\right)$}

The Chi-square test is a statistical test testing the adequacy of a data set to a family of probability laws or to test the independence between two random variables. The general principle consists in analyzing the gap between the theoretical distribution assumed and the empirical distribution obtained. In the results, what one must look at first and foremost is the P-value. It is the probability that the outcome variables considered are not significantly related to the treatment variable here climate change. So the smaller the $\mathrm{P}$-value, the more indisputable it is that the variables are linked. By convention, the 5\% threshold is often set. Thus, if the P-value is less than 0.05 , it can be said with not too much chance of being wrong that the variables are linked.

\section{2) Student Significance Test}

It refers to a set of parametric hypothesis tests where the calculated statistic follows a Student's law when the null hypothesis is true. It compares the measurements of a quantitative variable made on two groups of independent subjects defined by the modalities of the qualitative variable. A Student test can be used, in particular, to statistically test the hypothesis of equal expectation of two random variables according to a normal distribution and of unknown variance. This test compares the averages of two groups. The Student test is carried out in particular when the research involves two independent groups/samples and a quantitative dependent variable or if the participants in the studies have been measured twice (a repeated-measurement group) and the dependent variable is quantitative. The Student test therefore makes it possible to compare the means of these two groups (or measures) in order to infer a relationship between endogenous and exogenous variables. Like all statistical tests, the t-test makes it possible to reject or not the null hypothesis, and thus to make a statistical decision.

\subsubsection{Estimation Methods}

For the econometric analysis, the impact assessment method (teffects ra), an approach based on the calculation of the Average Treatment Effect $(A T E)$ as a parameter to be estimated, was used for estimation. These estimates are made by the statistical software STATA 15. The ATE parameter measures the average "treatment" effect on a randomly selected cotton farm over the two cotton production seasons 2011/2012 and 2015/2016. In this impact assessment context, "treatment" refers to the impact of climate change (distribution of rainfall over a given cotton growing period). Another parameter that will receive a lot of attention in this study is the average treatment effect on the treated (ATET). As its name suggests, $A T E T$ measures the average treatment effect on cotton farms impacted during the 2015/2016 cotton production season. 


\section{Results and Discussions}

\subsection{Econometric Analysis of the Impact of Climate Change on Cotton Production in the Savannah Region}

\subsubsection{Socio-Economic Characteristics of the Cotton Producers Surveyed}

It is important to remember that analytical data are collected over two periods (2011/2012 and 2015/2016 cotton production seasons) but from the same sample of cotton producers surveyed. Thus, empirical evaluation tests concluded that, from 2011/2012 cotton production season to 2015/2016, cotton farmers surveyed have retained the same socio-economic characteristics.

\subsubsection{Control Variables}

After the analysis of the fact that some variables may be impacted by climate change and thus violate the assumption of conditional independence, the choice of the control variables presented in Table 2 was made for estimation.

\subsubsection{Pearson Correlation Test Results and Interpretations}

At the end of the statistical analysis, the variables not correlated by climate change at the $5 \%$ threshold are: the respondent's sex, the respondent's age, the respondent's education, the respondent's marital status and the respondent's religion. These variables were used as control variables in the ATE model because they are not influenced by climate change.

\subsubsection{Results of Pearson's Chi-Square $\left(\chi^{2}\right)$ and Student's Significance} Tests between Treatment Variable and the Outcome Variables At the end of the statistical analysis, it appears there is a significant difference at the $1 \%$ threshold between the means of the quantitative variables of the two cotton production seasons (2011/2012 and 2015/2016) and a strong statistically significant relationship at the $1 \%$ threshold between the treatment variable (impact or not of climate change) and the outcome variables. The outcome variables (endogenous variables) are therefore explained by the treatment variable (exogenous variable). The results in Table 3 are obtained after performing the Chi-square $\left(\chi^{2}\right)$ and Student significance tests between the treatment variable and the outcome variables.

Table 2. Treatment variable and Control variables

\begin{tabular}{cc}
\hline Treatment variable & Heading \\
\hline TYPQUEST & Cotton farm status (1 if impacted and 0 otherwise $)$ \\
\hline Control variables & Heading \\
\hline SEX & Sex of the respondent \\
AGE & Age of the respondent \\
INSTRUC & Educational level of the respondent \\
SitMat & Marital status of the respondent \\
RELIGION & Religion of the respondent \\
\hline
\end{tabular}

Source: Author, 2016. 


\subsection{Discussions: Results of Econometric Estimates}

The econometric estimates of the parameters $A T E$ (Average Treatment Effect) and ATET (Average Treatment Effects on the Treated) based on STATA 15 software produced the results presented in Table 4.

$A T E$ : Impact of climate change on the randomly drawn dependent variable during the two cotton production seasons 2011/2012 and 2015/2016 (the population).

ATET: Impact of climate change on the dependent variable observed during the 2015/2016 cotton production season (impacted sub-population). From the results of the estimates, it is noted that the Average Treatment Effect $(A T E)$ is roughly equal to the Average Treatment Effect on the treated (ATET) because, climate change is an exogenous and random phenomenon over which cotton farmers have no control.

Thus the selection bias:

Table 3. Results of Pearson's Chi-square $\left(\chi^{2}\right)$ and Student's significance tests.

\begin{tabular}{ccc}
\hline Outcome variables & t-test & Pearson's $\left(\chi^{2}\right)$ \\
\hline Area of land sown & $-19.2076^{\star * *}$ & \\
Production & $-18.0570^{\star * *}$ & \\
Yield efficiency & $-57.7661^{\star * *}$ & \\
Income level & $-4.3252^{\star * *}$ & $306.1978^{\star * *}$ \\
Input credit consumption & & $139.0041^{\star * *}$ \\
Pest resistance & & $31.6698^{\star * *}$ \\
Soil fertility level & & \\
\hline
\end{tabular}

Notes: ${ }^{* * *}$, significant at $1 \%$; Source: Author, 2016.

Table 4. Results of the estimates.

\begin{tabular}{|c|c|c|}
\hline Outcome variables & ATE & ATET \\
\hline \multirow[t]{2}{*}{ Area of land sown } & $-0.4536895^{\star * *}$ & $-0.4637504^{* * *}$ \\
\hline & $(-3.52)$ & $(-3.55)$ \\
\hline \multirow[t]{2}{*}{ Production } & $-2260.259^{\star * *}$ & $-2329.858^{\star * *}$ \\
\hline & $(-10.54)$ & $(-9.46)$ \\
\hline \multirow[t]{2}{*}{ Yield efficiency } & $-510.0199^{\star * *}$ & $-514.7521^{\star * *}$ \\
\hline & $(-26.50)$ & $(-24.24)$ \\
\hline \multirow[t]{2}{*}{ Income level } & $-722.10^{* * *}$ & $-745.54^{* * *}$ \\
\hline & $(-12.00)$ & $(-10.37)$ \\
\hline \multirow[t]{2}{*}{ Consumption of input credits } & $0.942119^{* * *}$ & $0.9423775^{\star * *}$ \\
\hline & $(53.80)$ & $(53.35)$ \\
\hline \multirow[t]{2}{*}{ Pest resistance } & $0.5799078^{\star * *}$ & $0.5842342^{* * *}$ \\
\hline & $(-15.85)$ & $(-15.61)$ \\
\hline \multirow[t]{2}{*}{ Soil fertility level } & $-0.1690669^{* * *}$ & $-0.1695292^{\star * *}$ \\
\hline & $(-5.96)$ & $(-5.87)$ \\
\hline
\end{tabular}

Notes: ${ }^{* *}$, significant at $1 \%$; Income level is estimated in USD; Source: Author, 2016. 


$$
\beta=\left[E\left(Y_{0} \mid X=x, T=1\right)-E\left(Y_{0} \mid X=x, T=0\right)\right]=0
$$

In other words, $E\left(Y_{0} \mid X=x, T=1\right)=E\left(Y_{0} \mid X=x, T=0\right)$. This means that if climatic conditions were favourable for cotton production during the two observed cotton production seasons (2011/2012 and 2015/2016), all other things being equal, the average level of production would be the same [18] [20] [21].

\subsubsection{Impact of Climate Change on Land Sown Area}

The results of the econometric analyses show that climate change has a negative impact on sown area and this impact is significant at the $1 \%$ threshold. In the Savannah region, poor rainfall distribution over time and space leads to poor seedling start-up. This reduces the area sown per cotton farmer surveyed by an average of 0.45 hectare over the two cotton production season observed (2011/ 2012 and 2015/2016) and by 0.46 hectare over the cotton farms impacted in 2015. Despite unfavourable rainfall conditions, cotton farmers maintain their sowing intentions because cotton is the only cash crop in the region and cotton production is the only crop that allows them to have a significant annual income.

\subsubsection{Impact of Climate Change on Pest Resistance}

The results of the econometric analyses show that climate change has a positive impact on pest resistance. This impact is significant at the $1 \%$ threshold. In the Savannah region, climate change manifested by large pockets of drought favours pest resistance at 57.9\% on all observed cotton farms (2011/2012 and 2015/2016) and $58.4 \%$ on farms affected in 2015 . This resistance of the caterpillars is explained by the fact that, in recent years, in order to preserve the health of producers, the insecticides made available by the cotton sector to cotton producers have only killed caterpillar lava and not mature caterpillars. Thus, for the treatment to be effective, producers must respect the doses and treatment periods depending on the product while following the evolution of the cotton plant. Generally, it is advisable for cotton farmers to start phytosanitary treatments between the $30^{\text {th }}$ and $35^{\text {th }}$ day after sowing and to carry them out at a rate of 14 days according to a pre-established schedule and respecting the recommended products. It should also be remembered that a phytosanitary treatment needs a little moisture to be effective, but with the large pockets of drought recorded in recent years in the Savannah region, phytosanitary treatments are becoming almost ineffective, caterpillar lava is taking advantage of this to grow and become mature caterpillars and under these conditions, pest control is becoming very difficult.

\subsubsection{Impact of Climate Change on Soil Fertility Level}

The results of the econometric analyses show that climate change has a negative impact on soil fertility levels and this impact is significant at the $1 \%$ threshold. Econometric results reveal that in the Savannah region, climate change reduces soil fertility levels by $16.9 \%$ on all observed cotton farms (2011/2012 and 
$2015 / 2016$ ) and by $17 \%$ on cotton farms impacted in 2015 . This reduction in soil fertility is explained on the one hand by the fact that climate change manifested by drought and floods leads to soil degradation. On the other hand, the low level of soil fertility can also be explained by the fact that farmers do not practice soil fertility improvement techniques such as the use of organic manures of animal and plant origin, composting, the cultivation of fertilizing plants, integrated soil fertility management, etc. Also, due to demographic pressure, the land is no longer left fallow for long as before, which exacerbates the decline in soil fertility.

\subsubsection{Impact of Climate Change on Cotton Inputs Consumption}

The results of the econometric analyses show that climate change has a positive impact on input consumption and this impact is significant at the $1 \%$ threshold. In the Savannah region, climate change leads to an over-consumption of inputs of $94.21 \%$ in all the two cotton production seasons observed (2011/2012 and 2015/2016) and $94.24 \%$ during the 2015/2016 cotton production season. This over-consumption of inputs is explained on the one hand by the fact that pockets of drought and the absence of moisture make manuring and phytosanitary treatment operations ineffective. Thus, to hope for a good result at the end of the cotton production season, cotton farmer is obliged to multiply manure and especially phytosanitary treatment operations to make pest control effective, which increases his consumption of inputs. The over-consumption of cotton inputs can also be explained by the fact that a cotton farmer who does not benefit from food production input credits diverts inputs intended for cotton production to other crop production or even sometimes sells these cotton inputs on a "black" market.

\subsubsection{Impact of Climate Change on Production}

The results of the econometric analyses show that climate change has a negative impact on production and this impact is significant at the $1 \%$ threshold. In the Savannah region, climate change is leading to a reduction in production per cotton farmer surveyed by an average of $2260.259 \mathrm{~kg}$ on all observed cotton farms (2011/2012 and 2015/2016) and $2329.858 \mathrm{~kg}$ on cotton farms affected in 2015. It should be noted that climate change, manifested by increased temperatures associated with reduced rainfall and poor rainfall distribution, as revealed by climate analysis, weakens the supply-demand balance of soil water, leads to accelerated soil erosion and degradation, the establishment of drought pockets, pest resistance and would in turn contribute to a decline in cotton production and productivity in the Savannah region.

\subsubsection{Impact of Climate Change on Yield Efficiency}

The results of the econometric analyses show that climate change has a negative impact on yield and this impact is significant at the $1 \%$ threshold. In the Savannah region, climate change is causing a decrease in yield on average of 510.0199 $\mathrm{kg} / \mathrm{ha}$ on all cotton farms observed (2011/2012 and 2015/2016) and 514.7521 $\mathrm{kg} / \mathrm{ha}$ on cotton farms observed in 2015 . It should be noted that irregularity and 
poor rainfall distribution force cotton farmers to do more reseeding. Despite these repetitive reseeding, the density and population of cotton trees have been very low in recent years due to pockets of drought. However, technically, to have a good yield in the field (between 2500 and $3000 \mathrm{~kg} / \mathrm{ha}$ ), under the right rainfall conditions, it is necessary to be able to register 100,000 cotton plants on one hectare, i.e. 50,000 poquets at a rate of two feet per poquet. In addition to this low density, there is the ineffectiveness of crop maintenance (weeding, fertilization and phytosanitary treatments), the resistance of caterpillars and the decline in soil fertility levels. It should also be noted that the low yields are due to the reduction in the number of capsules per cotton plant, as a result of the low density recorded per hectare, the resistance of the caterpillars and especially the hydric stress resulting in the loss of the capsules by the plants due to lack of moisture. The technical results recorded at the end of the 2011/2012 and 2015/2016 cotton production seasons confirm this decline in yield. At the end of the 2011/2012 cotton production season, out of 41,524 poquets sown on average per hectare, 27,600 raised with 45,500 plants and 194,000 capsules. On the other hand, at the end of the $2015 / 2016$ cotton season, out of an average of 38,837 poquets sown per hectare, 28,632 raised with 49,079 plants and 185,772 capsules, while the minimum number of capsules per hectare is 400,000 [22].

\subsubsection{Impact of Climate Change on Income Level}

The results of the econometric analyses show that climate change has a negative impact on income levels and this impact is significant at the $1 \%$ threshold. Climate change is leading to a reduction in income on average by US $\$ 722$ per producer in Savannah region which was surveyed on all observed cotton farms (2011/2015 and 2015/2016) and US $\$ 745$ per producer which was surveyed on cotton farms affected in 2015. The decline in income is only a direct consequence of the decline in physical productivity (yield) and the increase in production costs (over-consumption of inputs).

In conclusion, the results obtained confirm the hypotheses formulated and are in line with the results of previous studies, in particular, the final report on the impact of climate change: analysis of poverty-related aspects in Togo [23] and the final report of the Unified Questionnaire of Basic Indicators of Wellbeing in Togo [24].

\section{Conclusions and Recommendations}

\subsection{Conclusions}

This research explored the impact of climate change on cotton production in the Savannah region. Its main objective was to evaluate the impact of the variability of the rainfall distribution on the observed production of cotton farmers with a view to improving the performance of cotton sector. It used primary data from surveys conducted by the author among cotton farmers in the Savannah region of Togo. The SPSS 20 statistical software was used as a database for econometric 
analysis. The impact assessment method, an approach based on the estimation of the ATE parameter (Average Treatment Effects) based on the STATA 15 statistical software, was used to assess the impact of climate change on cotton production while taking into account the cotton producers' responses. Thus, the study found that as climate change manifests itself in rising temperatures, poor rainfall distribution creating large pockets of drought has a negative impact on cotton production in the Savannah region. The results of the econometric estimation show that:

Climate change has a significant negative impact at the $1 \%$ threshold on the area sown by producers because of the difficulties that cotton farmers have had in recent years in identifying the effective start of rainy seasons and in repetitive sowing. Despite this negative impact, cotton farmers maintain their sowing intentions since cotton is the only cash crop in the region and cotton-crop is the only crop production on which producers rely for a significant annual income.

Climate change has a significant negative impact at the $1 \%$ threshold on soil fertility levels through soil degradation, drought and flooding. Climate change has a significant positive impact at the $1 \%$ threshold on the resistance of caterpillars. Large pockets of drought caused by irregularities and poor rainfall distribution make phytosanitary treatments ineffective due to lack of moisture, resulting in the development of caterpillars that are difficult to control at the maturity stage. Climate change has a significant positive impact at the $1 \%$ threshold on the consumption of input credits due to the absence of humidity and pockets of drought making manure and phytosanitary treatment operations ineffective. Climate change has a significant negative impact at the $1 \%$ threshold on production and physical productivity (yield) due to low seeding rates, hydric stress of plants due to lack of moisture, resistance of caterpillars and declining soil fertility levels. Climate change has a significant negative impact at the $1 \%$ threshold on income level. As the capacity of cotton producers in the Savannah region to adapt to climate adverse effects is very low, the consequences of climate change on their daily lives mainly concern the overconsumption of input credits, leading to an increase in production costs, a decrease in cotton crop yields and, consequently, a decrease in their net income after cotton marketing and, in the worst case, debt.

Thus, climate is a potential threat to cotton production in Savannah region and will therefore increase poverty and reduce the well-being of cotton farmers in rural areas. Producers will see their existence affected, in the absence of appropriate interventions by public authorities and all other actors in the cotton sector. As the adaptation strategies of the cotton farmers surveyed are very weak, it is therefore essential that efforts be made to adapt to and/or mitigate the effects of climate change. Thus, this study recommends two main areas of intervention: the promotion of adaptation options to climate change adverse effects by controlling the physical and socio-economic determinants of cotton production and the development of new adaptation options by addressing the risks to 
which producers are exposed.

\subsection{Recommendations}

In view of the above, the following recommendations are made:

\subsubsection{With Regard to Public Authorities}

The Government and Non-Governmental Organizations should seek funding for the implementation of effective climate change adaptation strategies; the establishment of an agro-meteorological warning system to provide producers with information on rainy season prediction; the promotion of agricultural credit to facilitate the timely financing of producers' production; the promotion of activities to diversify sustainable sources of income such as improved traditional breeding and agricultural food processing; the strengthening of agricultural mechanization policy through the National Programme for Agricultural Investment and Food Security.

\subsubsection{With Regard to Extension and Support Services}

The expansion of sown areas must be accompanied by the availability of short-cycle, high-yield, drought-resistant varieties and highly effective treatment products for cotton farmers; raising producers' awareness of the reality of climate change; training and information sessions must be organized for farmers to protect their environment and better adapt to climate change; prioritize climate change issues in their action agenda; the study from a participatory approach perspective, the possibilities of popularizing agroforestry systems in order to enable producers to limit the decrease in their income due to the drop in crop yields induced by climate change; supporting producers in reforestation operations to protect the soil against erosion; easy access to credit, especially financial credit must be granted to farmers.

\subsubsection{For Farmers}

The development of a sincere collaboration with extension and supervision services in order to take advantage of the exogenous knowledge promoted by these structures; sharing adaptation experiences among producers.

\subsubsection{At the Research Location}

The development, with a view to a participatory approach that integrates the socio-economic conditions of producers, of short-cycle varieties adapted to current climatic conditions; the development of research on water management techniques to reduce the heavy dependence of agriculture in general and cotton production in particular on rainfall; the development of research for the production of bio fertilizers, bio-insecticides and varieties that can better withstand rainfall breaks during the rainy season to improve crop yields.

This study is a first step in assessing the impact of climate change on cotton production in the Savannah region of Togo. Even if the nature of the data used 
did not properly allow capturing the full dimension of climate change impact, the results obtained after econometric analyses are significant and not negligible. The conclusions of this research concern only the two observed cotton production seasons (2011/2012 and 2015/2016). Since climate change evolves both in time and space, it is desirable that this research be continued in the short run on others cotton production seasons with a higher number of cotton farmers surveyed, and in the long run by using time series data to assess the impact of climate change on cotton production in Togo.

\section{Acknowledgements}

The authors are very grateful to German Academic Exchange Service (DAAD) for funding the publication of this paper.

\section{Conflicts of Interest}

The authors declare no conflicts of interest regarding the publication of this paper.

\section{References}

[1] CEDEAO (2005) Memorandum on the Challenges of the Agricultural Sector in ECOWAS Foreign Trade Policy. Implications for the Negotiation of the Economic Partnership Agreement with the European Union. https://www.alimenterre.org

[2] Gauthier, J. and Langlois, A.M. (2010) National Programme for Agricultural Investment: PNIASA. Investment Plan 2010-2015. Lome-Togo. https://www.lse.ac.uk/

[3] NSCT and FNGPC (2013) Strategy to Improve the Productivity and Quality of Seed Cotton, Lomé-Togo.

[4] Mqadi, L. (2005) Production Function Analysis of the Sensitivity of Maize Production to Climate Change in South Africa. 110 p. http://hdl.handle.net/2263/28380

[5] WIPO (2009) Climate Change-The Technology Challenge. https://www.wipo.int

[6] Mendelsohn, R., Nordhaus, W. and Shaw, D. (1994) The Impact of Global Warming on Agriculture: A Ricardian Analysis. The American Economic Review, 84, 753-771. http://www.jstor.org/stable/2118029 https://doi.org/10.1257/aer.89.4.1046

[7] Cline, W.R. (1996) The Impact of Global Warming on Agriculture: Comment. The American Economic Review, 86, 1309-1311. http://www.jstor.org/stable/2118295

[8] IPCC (2007) Climate Change 2007. Mitigation of Climate Change. Contribution of Working Group III to the Fourth Assessment Report of the Intergovernmental Panel on Climate Change. https://www.ipcc.ch

[9] Mendelsohn, R. and Dinar, A. (2003) Climate, Water, and Agriculture. Land Economics, 79, 328-341. https://www.jstor.org/stable/3147020 https://doi.org/10.2307/3147020

[10] Gbetibouo, G.A. and Hassan, R.M. (2004) Measuring the Economic Impact of Climate on Major South African Field Crops: A Ricardian Approach. Glob Planet Chang, 47, 143-152. https://doi.org/10.1016/j.gloplacha.2004.10.009

[11] Molua, E. and Lambi, C. (2006) The Economic Impact of Climate Change on Agri- 
culture in Cameroon. CEEPA Discussion Paper No. 17, Centre for Environmental Economics and Policy in Africa, University of Pretoria, Pretoria. The World Bank, Policy Research Working Paper Series.

https://doi.org/10.1596/1813-9450-4364

[12] Nefzi-Bouzidi, A. (2012) Economic Evaluation of the Impact of Climate Change on Agriculture: Theoretical Study and Application to the Case of Tunisia. Ecology, Environment. AgroParisTech.

[13] FAO (2007) Interdepartmental Working Group on Climate Change and Food Security: A Framework Document. Rome. http://www.fao.org/home/en/

[14] ACA African Cotton Association (2014) Twelfth Conference of the African Cotton Association Held in Yamoussoukro. https://www.news.abidjan.net

[15] Fellegi, I.P. (2003) Survey Methods and Practices. Catalogue $N^{\circ} 12-587-X$. Ottawa. https://www150.statcan.gc.ca

[16] IPCC (2007) Climate Change 2007. Impacts, Adaptation and Vulnerability. Working Group II Contribution to the Fourth Assessment Report of the Intergovernmental Panel on Climate Change. https://www.ipcc.ch

[17] Koffi-Tessio, E.M. (2009) Modelling Climate Change and Agricultural Production in Sub-Saharan Africa (SSA): In Quest of Statistics. 2009 Conference, August 16-22, 2009, Beijing, China. 50821, International Association of Agricultural Economists. https://ideas.repec.org/p/ags/iaae09/50821.html

[18] Rubin, D. (1974) Estimating Causal Effects of Treatments in Randomized and Non Randomized Studies. Journal of Educational Psychology, 66, 688-701. https://doi.org/10.1037/h0037350

[19] Fougère, D. (2007) Micro-Econometric Evaluation Methods. Working Papers 166, Bank of France, Paris. https://ideas.repec.org/p/bfr/banfra/166.html

[20] Heckman, J.J. and Robb, R. (1985) Alternative Methods for Evaluating the Impact of Interventions. In: Heckman, J.J. and Singer, B., Eds., Longitudinal Analysis of Labor Market Data, Cambridge University Press, New York, 156-245. https://doi.org/10.1016/0304-4076(85)90139-3

[21] Heckman, J.J. and Robb, R. (1986) Alternative Methods for Solving the Problem of Selection Bias in Evaluating the Impact Treatment on Outcomes. In: Wainer, H., Eds., Drawing Inferences from Self-Selected Samples, Springer-Verlag, New York, 63-107. https://doi.org/10.1007/978-1-4612-4976-4_7

[22] DRCN (2016) North Cotton Production Region. Technical Report: Analysis of the 2009/2010 to 2015/1016 Cotton Production Season.

[23] UNDP (2011) The Impact of Climate Change: Analysis of Poverty Components in Togo. Final Report of December 19, 2011.

[24] QUIBB-TOGO (2015) Questionnaire of Basic Indicators of Wellbeing in Togo in 2015. Final Report. http://www.stat-togo.org/ 